\title{
IDENTIDADES CONTINGENTES E CULTURA MATERIAL NA PÓS-MODERNIDADE
}

\section{CONTINGENT IDENTITIES AND MATERIAL CULTURE IN POSTMODERNITY}

\author{
IDENTIDADES CONTINGENTES Y CULTURA MATERIAL EN LA POST \\ MODERNIDAD
}

\author{
Marcos Sardá Vieira ${ }^{1}$ \\ https://orcid.org/0000-0002-0263-0992
}

\begin{abstract}
Submissão: 27/02/2021 / Aceito: 17/06/2021 / Publicado: 30/09/2021.
\end{abstract}
\begin{abstract}
Resumo
A vanguarda dos movimentos feministas e homossexuais tomou a dimensão pública do questionamento da modernidade desigual, requerendo autonomia às mulheres e reconhecimento às dissidências sexuais, diante de uma sociedade machista e preconceituosa. De alguma maneira, esses movimentos foram importantes para tornar real a problemática de uma materialidade não representativa para corpos, identidades e desejos em desacordo com a ordem e a moralidade constituídas na modernidade. Contudo, no contexto da pósmodernidade, onde a cultura material ainda atende aos desejos predominantes da cisheterossexualidade masculina, quais as contribuições do feminismo e das sexualidades queer para descentrar os significados do planejamento urbano homogêneo e fomentar novas representações identitárias? No âmbito cultural, será que podemos considerar o conceito de modernidade líquida relativa apenas às identidades femininas e dissidentes enquanto para as tradições institucionais permaneceria a sólida concepção da materialidade cartesiana? Através de revisão bibliográfica e análise interdisciplinar, apresentamos algumas experiências de urbanidades conformadas pelo senso de reciprocidade e respeito à diversidade.
\end{abstract}

Palavras-chave. Pós-modernidade. Feminismos. Sexualidades. Urbanidade.

\begin{abstract}
The vanguard of feminist and homosexual movements took on the public dimension of questioning unequal modernity, requiring autonomy for women and recognition of sexual dissent, in the face of a sexist and prejudiced society. In some way, these movements were important to make real the problem of a nonrepresentative materiality for bodies, identities and desires in disagreement with the order and morality constituted in modernity. However, in the context of postmodernity, where material culture still meets the predominant desires of male cisheterosexuality, what are the contributions of queer feminism and sexualities to decentralize the meanings of homogeneous urban planning and foster new identity representations? In the cultural sphere, can we consider the concept of liquid modernity relating only to feminine and dissident identities while for institutional traditions the solid conception of Cartesian materiality would remain? Through bibliographic review and interdisciplinary analysis, we present some experiences of urbanities conformed by the sense of reciprocity and respect for diversity.
\end{abstract}

Keywords. Postmodernity. Feminisms. Sexualities. Urbanity.

\section{Resumen}

La vanguardia de los movimientos feministas y homosexuales asumió la dimensión pública de cuestionar la modernidad desigual, exigiendo la autonomía de las mujeres y el reconocimiento de la disidencia sexual, frente a una sociedad sexista y prejuiciosa. De alguna manera, estos movimientos fueron importantes para hacer real el problema de una materialidad no representativa de cuerpos, identidades y deseos en desacuerdo con el orden y la moral constituidos en la modernidad. Sin embargo, en el contexto de la posmodernidad,

\footnotetext{
${ }^{1}$ Doutor em Ciências Humanas e professor adjunto da Universidade Federal da Fronteira Sul (UFFS). DOI: http://dx.doi.org/10.22295/grifos.v31i55.6135 | Edição Vol. 31, Núm. 55, 2022.
} 
donde la cultura material todavía satisface los deseos predominantes de la cisheterosexualidad masculina, ¿cuáles son las contribuciones del feminismo y las sexualidades queer para descentralizar los significados de la planificación urbana homogénea y fomentar nuevas representaciones de identidad? En el ámbito cultural, ¿podemos considerar el concepto de modernidad líquida relacionándose únicamente con identidades femeninas y disidentes mientras que para las tradiciones institucionales se mantendría la sólida concepción de la materialidad cartesiana? A través de la revisión bibliográfica y el análisis interdisciplinario, presentamos algunas experiencias de urbanidades conformadas por el sentido de reciprocidad y respeto por la diversidad.

Palabras llave: Posmodernidad. Feminismos. Sexualidades. Urbanidad.

\section{INTRODUÇÃO}

Neste artigo ${ }^{2}$ tratamos da experiência contingente de identidades sexuais e de gênero diante de condições de urbanidade ainda pautadas pela cultura material de apegos para a configuração de discursos e objetos. Em contraponto ao conjunto de valores e saberes de uma cultura predominante, discutimos sobre o caráter transformador das subculturas da pós-modernidade, envolvidas no descentramento de subjetividades identitárias, e sua relativa influência sobre a cultura material e urbana ainda pautada pela modernidade.

$\mathrm{Na}$ experiência dos modos binários de ser homem e ser mulher na sociedade ocidental do início do século 20, em dissonância com o devir das novas identidades sexuais da atualidade, surgem outras perspectivas e significados para as relações sociais e particulares diante do conceito de urbanidade, como processo de convivências e valores sociais intercambiáveis e de múltiplas possibilidades articuladas ao espaço urbano. Nesse descompasso surgem as seguintes perguntas: de que maneira a constituição de discursos e objetos de representação da realidade atual acompanha a constituição líquida de identidades de gênero e sexualidades para além das categorias de regulamentação do sujeito sociológico nascido no Iluminismo? Quais as traduções e os novos significados estabelecidos para a representação das coisas em urbanidades promovidas pela subjetividade de sujeitos-corpos líquidos, descentrados da sólida cis-heterossexualidade ${ }^{3}$ masculina?

Pela perspectiva das práticas cotidianas do desvio à ordem hegemônica, o objetivo principal dessa publicação é refletir sobre a constituição da representação de subculturas na urbanidade contemporânea a partir da ressignificação do sujeito pós-moderno não mais centrado em categorias

\footnotetext{
2 Este artigo é parte da linha de pesquisa "Gênero, espaço e sexualidades" desenvolvida pelo GIGRAS (Grupo Interdisciplinar em Gênero, Raça e Sexualidades), grupo de pesquisa vinculado à Universidade Federal da Fronteira Sul (UFFS).

${ }^{3} \mathrm{O}$ termo cis-heterossexualidade é relativo à orientação heterossexual de pessoas que se identificam, em todos os aspectos, com o gênero/sexo de nascença. Esse termo é destacado para evidenciar o contraponto com a heterossexualidade de pessoas trans, ao se identificarem em oposição ao gênero/sexo atribuído no nascimento. Portanto, ao destacar a constituição de identidades sólidas, nos referimos às pessoas cis-heterossexuais.
}

DOI: http://dx.doi.org/10.22295/grifos.v31i55.6135 | Edição Vol. 31, Núm. 55, 2022.

Este é um artigo publicado em acesso aberto (Open Access) sob a licença Creative Commons Attribution, que permite uso, distribuição e reprodução em qualquer meio, sem restrições desde que o trabalho original seja corretamente citado. 
de regulamentação cis-heteropatriarcal, ou mesmo na desconstrução da cultura material urbana voltada para o apego material e discursivo consolidados pela modernidade.

Por meio de revisão bibliográfica, observação não participante ${ }^{4}$ e abordagem interdisciplinar, relacionando às temáticas "gênero, espaço e sexualidades", esta publicação destaca a consolidação da cultura material e urbana, relativamente, mais concreta e uniforme para atender as necessidades e desejos cis-heteronormativos e masculinos, em contraste com a constituição de subjetividades fluídas, que se tornam diversas entre identidades e sexualidades contingentes, representadas, principalmente, pelos movimentos feministas e as dissidências (pós) identitárias de lésbicas, gays, bissexuais, transexuais/travestis e intersexuais (LGBTI). Ao final, consideramos que as vivências de comunidades e grupos sociais inspirados pelos feminismos e pelas dissidências de gênero e sexualidades permitem rever a relação das pessoas com a cultura material e com as políticas públicas, ainda voltadas à condição de urbanidades centradas por estratégias biopolíticas de conservação de desejos e representações cis-heteropatriarcais.

\section{CULTURA MATERIAL E CIDADE CONTEMPORÂNEA}

Para Zygmunt Bauman (1999) os novos arranjos identitários marcados pela ambiguidade e nomeados por mais de uma categoria são parte da modernidade e, cada vez mais, estão presentes na pós-modernidade, chamada pelo sociólogo de modernidade líquida. Segundo o autor, quando nos desvinculamos da solidez modernista surge a ambiguidade como produto da linguagem, ao permitir nomear um objeto ou evento em mais de uma categoria, fugindo da ordem oficial do significado estável e gerando insegurança. Para a tradição modernista, classificar significa separar, segregar e dar ao mundo uma estrutura ordenada, que elimina a causalidade dos fatos e permite atos de inclusão e exclusão do que não é classificável. De acordo com o autor, um mundo ordeiro é um mundo no qual a gente sabe como ir adiante, ao controlar a probabilidade de um determinado evento obter sucesso ou não. Por isso, a modernidade se definiu como um período de combate implacável contra a ambivalência, ao atribuir ordenamento como sua principal tarefa e tornando a intolerância contra o caos sua principal prática.

Essa distinção sócio-política, de uma nova racionalidade pautada na economia de produção e funcionamento social, se refletiu no planejamento urbano modernista do final do século 19, ao

\footnotetext{
${ }^{4} \mathrm{O}$ método de observação não participante diz respeito ao levantamento de campo realizado em Tempelhof/ Berlin e Christiania/ Compenhagen em 2016 - localidades citadas na parte final deste artigo. DOI: http://dx.doi.org/10.22295/grifos.v31i55.6135 | Edição Vol. 31, Núm. 55, 2022. 
idealizar e tornar as cidades mais higiênicas, homogêneas e produtivas tanto pela regulamentação das funções espaciais quanto pelos comportamentos e perfis humanos, baseados na política da heterossexualidade compulsória e na estrutura de relações patriarcais. Assim, a cidade modernista do século 19 concebeu e abrigou uma ordem de sujeitos resilientes, cujas normas de identidade deveriam estar orientadas para o desejo heterossexual, na condição binária e estável (entre feminino ou masculino) em sua inserção identitária e sociológica. Para centralizar essa condição de regulamentação, entretanto, foi necessário excluir do reconhecimento público e moral as pessoas e as identidades ambíguas, classificadas como anormais diante da expressão do corpo, comportamentos e desejos, que desafiavam a integridade cisheterossexual como norma. Em consonância, a consolidação dessa regulamentação do gênero e das sexualidades pela cultural material modernista resultou na configuração urbana de um cenário propício para a representação do desejo cisheterossexual masculino. Nesse sentido a consolidação da arquitetura das cidades pelo planejamento urbano imprimiu o espaço uniforme e funcional como medida de controle e eficiência. Assim, seguindo essa concepção da cidade como máquina, distinguindo funções para a moradia, a circulação, o trabalho e o lazer, não houve espaço oficial e central para as reinvenções culturais e as interações sociais de informalidade (DARDOT e LAVAL, 2016; FOUCAULT, 2014; SPOSITO, 2012).

Segundo Ana Fernandes (2006) a relação entre cidade e cultura se insere na atualidade pela apropriação do tempo, da memória e da produção cultural, que são reduzidos aos interesses mercantis, ao transformarem os valores de objetos de arte, tradições populares, objetos do cotidiano e as memórias patrimoniais em reedições vazias de conteúdo para a circulação e consumo. Portanto, a partir da racionalidade estratégica das corporações privadas a cidade torna-se o objeto cultural a ser reocupado em seus valores voltados para a celebração do caráter privado, produzindo cenários e representações de legitimação dos novos valores ligados ao sucesso e a qualidade das corporações no âmbito coletivo. Entretanto, a abrangência desse regime de ruptura econômico-social predominante na organização das novas centralidades urbanas não alcança, da mesma maneira, todos os âmbitos da cidade, principalmente, daquele contexto excluído de seus modos de consumo. Assim, apesar do caráter excludente e técnico da ordem urbana espetacular, também surge a dimensão de subculturas periféricas com diferentes lógicas e formas de sociabilidade, ao reelaborar esses conteúdos, ou mesmo, questioná-los (FERNANDES, 2006). 
O fenômeno de mercantilização da cidade e da urbanidade está presente na constituição histórica do ambiente urbano. Entretanto, é na modernidade que se intensifica a produção do espaço urbano enquanto valor de troca. Em geral, essa prática de constituição das cidades ocidentais foi estabelecida pelas grandes reformas urbanas no auge da modernidade industrial, no final do século 19. Nesse contexto histórico, a reforma urbana promovida em Paris permanece como a principal referência de conciliação entre os princípios estilísticos e higienistas da modernidade com os avanços técnicos e administrativos de uma racionalidade capitalista ascendente. É nesse período que surgem novos materiais e técnicas construtivas utilizando o aço e o concreto, por exemplo; na configuração de parques e áreas livres públicas dentro da malha urbana, na livre criação de uma natureza artificial e regulamentada; e, ainda, na distinção da unidade arquitetônica com o tecido urbano, criando-se ornamentações luxuosas e neoclássicas, que distinguiam a classe burguesa dos proletariados (LIMA e CARVALHO, 2011).

Em geral, a cultura material e urbana da modernidade tornou cativo o conjunto de fatos urbanos oficiais para atender aos interesses econômicos, relegando medidas secundárias para as necessidades e prazeres sociais. Ao estabelecer o controle sobre as funções urbanas, consolidaramse os meios de produção sob as política cisheteronormativa, baseada na estabilidade da vida uniforme e factível onde o gênero masculino torna-se supremo na apropriação da esfera pública e no valor simbólico de representação social (LIMA e CARVALHO, 2011).

O planejamento urbano, como metodologia e prática de ordenação do espaço, costuma seguir os valores econômicos estabelecidos pela cultura corporativa sobre os interesses predominantes da sociedade, ao mesmo tempo em que reduz a possibilidade de outras vivências urbanas, que fujam dessa prerrogativa econômica e ideológica, sob a justificativa dos interesses de investimento voltados para um caráter moral e higienista da cultura material e imaterial predominantes. De maneira subliminar, essa tem sido a condição da nova cultura voltada para os interesses especulativos do espaço urbano como dispositivo cativo de regulamentação e disciplina para o consumismo.

Entretanto, por mais que essas reformas urbanas de consolidação da produção econômica (tanto na Europa no final do século 19 quanto na América Latina ao longo do século 20) tenham gerado cidades icônicas e espetaculares, a presença de modos alternativos de vida e as subculturas urbanas continuaram permeando as áreas públicas de convivência e ocupando as estrias dos espaços não regulamentados e periféricos. Inclusive, as identidades vistas como subversivas, representadas 
por corpos e comportamentos de prostitutas, homossexuais e sujeitos de expressão de gênero ambivalente, continuaram presentes nos espaços públicos e clandestinos dos grandes centros urbanos.

A partir da segunda metade do século 20 o planejamento das cidades ocidentais é revisto diante da experiência de reconstrução das metrópoles, destruídas durante a Segunda Guerra Mundial. Com esses novos arranjos espaciais foram reduzidas as barreiras físicas e geográficas, aumentando o potencial de circulação das pessoas, os processos de migração e as interações com o mercado de trabalho e consumo, de produtos e informações. Nesse sentido, os principais centros urbanos, com maior fator de atração ao contingente populacional e investimentos econômicos, adaptaram-se para a amplitude do mercado e da comunicação mundial. É nesse âmbito que surgem as cidades globais defendidas pela socióloga Saskia Sassen (2005), conferindo centros de produção científica e tecnológica para impulsionar a economia e os centros de pesquisa e criatividade. É interessante notar que essa concepção de cidades globais já não depende, totalmente, do espaço físico para estabelecer suas conexões e gerar novos significados. Por isso, à ordem do espaço como campo de atuações econômicas e sociais também se torna o meio para viabilizar a infraestrutura tecnológica da comunicação virtual de sociedades e instituições.

Nesse contexto de mudanças e novas inserções tecnológicas, a esfera pública deixa de limitar-se apenas ao espaço coletivo e presencial da cidade. As experiências do público e do privado se entrecruzam através do repasse digital de informações (textos e imagens) e dos discursos midiáticos (LYOTARD, 2009). O que relativiza a necessária vinculação entre identidade e corporalidade na integração do sujeito. Ou seja, a informação digital torna possível antecipar a identificação discursiva do sujeito em relação a sua experiência presencial, criando simulacros identitários virtuais e, ao mesmo tempo, intensificando os estímulos e as interações com o aumento das informações e valores culturais.

Enquanto na cidade modernista o espaço urbano definiu fronteiras físicas e subjetivas para a regulamentação dos valores sociais, no espaço virtual da atualidade esses valores são resignificados por experiências cotidianas efêmeras e pelo sistema produtivo. Na própria restrição das mulheres no âmbito do espaço privado ou a invisibilidade de sujeitos "anormais" no espaço público, essas representações são reapropriadas por imagens e discursos, que se misturam na liquidez de novas identidades e reconstituem o espaço transitório entre diferentes localidades. O que gera ressentimento nas mentalidades mais tradicionais.

DOI: http://dx.doi.org/10.22295/grifos.v31i55.6135 | Edição Vol. 31, Núm. 55, 2022. 
Assim, a materialidade surgida na modernidade concreta das cidades perde a ênfase no contexto peculiar de seus arranjos sociais diante da repetição indiscriminada de imagens e da ressignificação constante de sua aparência para atender múltiplas finalidades de consumo e entretenimento. Nesse contexto, vários arranjos de discursos e objetos possibilitam novos processos de identificação aos sujeitos em períodos de tempo cada vez mais curtos, que aos poucos vão sendo incorporados nas vivências presenciais e na esquizofrenia das áreas de convivência e circuitos de apropriação turística.

São nesses processos transitórios de constituição de sujeitos e lugares, que a pósmodernidade vai sobrepondo e descartando significados e aparências à dinâmica paisagística e nas ruínas arquitetônicas de passados recentes. Ao mesmo tempo, é na descontinuidade da relação tempo-espaço que as ondas invisíveis de transformação desalojam as relações sociais de suas localidades e tradições para estabelecer outras esferas do domínio na reconfiguração de estruturas materiais e simbólicas pautadas pela viabilidade econômica.

\section{TRANSFORMAÇÕES IDENTITÁRIAS NA PÓS-MODERNIDADE}

De acordo com Stuart Hall (2006), esse âmbito de transformações ocorridas a partir dos anos 1960 trouxe descontinuidade na maneira de conceber identidades homogêneas com base na estabilidade do sujeito moderno e sociológico. Os processos de classificação das condições de vida na interpretação do sujeito cartesiano, pautado na estabilidade e unidade do sujeito racional, sofreram abalos com os avanços teóricos, os movimentos sociais e os pensamentos críticos da sociedade industrial. É nesse sentido que o autor caracteriza a pós-modernidade (ou a modernidade tardia) pela inconstância e descentramento identitário do sujeito moderno. Ou seja, o que era definido como identidade para a constituição do indivíduo fixo e estável, em sua representação como sujeito do Iluminismo no século 18 , torna-se descontínuo nos processos de subjetivação do indivíduo junto ao devir dos fenômenos sociais marcados pela transgressão crítica do pensamento racional desde o início do século 20.

Assim, do sujeito racional e consciente da modernidade, preso em uma ordem de classificação social e hierárquica inquestionável, surge a possibilidade de transformação através do sujeito sociológico da pós-modernidade, alterando seu processo de identificação no curso de vida, diante dos avanços da teoria social e das Ciências Humanas (que alteraram a perspectiva do DOI: http://dx.doi.org/10.22295/grifos.v31i55.6135 | Edição Vol. 31, Núm. 55, 2022. 
pensamento histórico como causalidade não intencional). Na medida em que o sujeito deixa de ser o centro do controle sobre a compreensão da realidade, por não se basear na investigação empírica para obter todas as respostas - e no controle de seus anseios psíquicos, a racionalidade deixa de ser a estrutura principal sob a qual se constrói a identidade do sujeito contemporâneo.

Essa mudança de perspectiva para a inserção do sujeito em sua realidade reflete mudanças na própria constituição dos discursos e do pensamento na pós-modernidade. Colaborando nesse contexto de descentramento do sujeito cartesiano, Hall (2006) destaca cinco grandes avanços da teoria social e das Ciências Humanas a partir do século 20: (1) a retomada das tradições do pensamento marxista, ao considerar a impossibilidade de agenciamento individual diante das condições históricas, dos recursos materiais e da cultura predominante, que são fornecidos e condicionados pelas gerações anteriores; (2) a descoberta do inconsciente pela psicanálise de Freud, ao conceber a hipótese de que nossas identidades, nossas sexualidades e a estrutura dos desejos são determinados por processos psíquicos e simbólicos do inconsciente e fora do domínio da lógica do sujeito cognoscente e racional; (3) o trabalho desenvolvido pelo linguista estrutural Ferdinand Saussure, para quem a língua é um sistema social e não individual, utilizada como meio de expressão e que não nos permite criar novos significados individuais a partir de sua estrutura. Apesar de a estrutura da linguagem ser instável e aberta a novos significados, essa construção está fora de controle do indivíduo. Segundo a obra de Saussure, a linguagem é quem promove a influência com sua estrutura simbólica sobre a constituição e identificação do sujeito através da relação entre similaridades e diferenças; (4) o trabalho do filósofo e historiador Michel Foucault sobre a genealogia do sujeito moderno ao evidenciar o poder disciplinar como meio de regulamentação, vigília e governo da espécie humana, centrando-se também na disciplina do indivíduo e do seu corpo. "O objetivo do poder disciplinar consiste em manter as vidas, as atividades, o trabalho, a infelicidade e os prazeres do indivíduo, assim como sua saúde física e moral, suas práticas sexuais e sua vida familiar, sob estrito controle e disciplina" (HALL, 2006, p. 42).

A quinta mudança apontada por Stuart Hall (2006) refere-se ao feminismo como movimento social e crítica teórica, que ganha maior projeção junto de outros movimentos sociais surgidos nos anos 1960, entre eles, os movimentos ambientalistas. Na interpretação do autor, o feminismo teve uma relação mais direta no deslocamento conceitual do sujeito cartesiano e sociológico porque questionou a distinção entre público e privado (dentro e fora) da ordem moderna. Ao mesmo tempo, o feminismo contestou o papel político das instituições familiares, da sexualidade, do trabalho DOI: http://dx.doi.org/10.22295/grifos.v31i55.6135 | Edição Vol. 31, Núm. 55, 2022. 
doméstico, entre tantas outras classificações; hierarquias e funções sociais marcadas pelas relações de gêneros binários. Segundo o autor o feminismo também problematizou a subjetividade, a identidade e o processo de identificação do gênero, segmentado pelo contraste entre masculino ou feminino na sociedade moderna, além da própria formação estanque para a orientação sexual. Por fim, o feminismo trouxe à tona a questão da diferença sexual, desfazendo a ideia de que os homens e as mulheres fazem parte da mesma identidade e que compartilhariam, nessa associação, dos mesmos desejos na constituição de uma realidade única e padrão.

Hall (2006) ainda nos faz refletir sobre a contingência na constituição de identidades e a noção de nacionalidade, que se alteram devido aos processos migratórios promovidos pela globalização. Essas mudanças, apontadas pelo autor, surgem pelo aumento da circulação das pessoas entre diferentes territórios mundiais devido a processo migratórios, que se tornaram mais intensos a partir da maior permeabilidade geográfica entre países e do fator de atração das metrópoles na segunda metade do século 20. Dessa forma, a maneira como cada imigrante passa a se vincular ao novo contexto geográfico, urbano e sociocultural cria um deslocamento para a sua constituição como sujeito diante da nova identidade nacionalista, que é diferente da perspectiva de quem nasceu nesse mesmo local. Ao mesmo tempo, torna-se uma experiência distinta da condição identitária definida pelo contexto de origem do sujeito deslocado.

Apesar dos movimentos anticolonialistas, feministas e abolicionistas do final do século 19, apenas na segunda metade do século 20 surgem às demandas efetivas decorrentes dessas manifestações sociais requerendo direitos civis e questionando os ideais universais do imperialismo ocidental. O movimento feminista destaca-se como ideário social ao longo do século 20 , ao diversificar a potência de identidades coletivas e femininas na construção de vivências e epistemologias, que acompanham e se adaptam às transformações culturais da pós-modernidade, renovando sua agenda e requerendo autonomia ao corpo e a sexualidade das mulheres (MISKOLCI, 2015).

\section{FEMINISMOS E SUBJETIVIDADES NA TRANSFORMAÇÃO DO COTIDIANO}

Compreender o feminismo como mobilização social e epistemológica é fundamental para que possamos compreender todos os movimentos e teorias surgidas em decorrência dessa corrente humanista, como as teorias gays, lésbicas e queer, que surgiram do posicionamento crítico das/dos

DOI: http://dx.doi.org/10.22295/grifos.v31i55.6135 | Edição Vol. 31, Núm. 55, 2022. 
feministas e pela reformulação crítica dos conceitos de gênero e sexualidades. Em geral, todos os movimentos vinculados às problemáticas feministas procuram reduzir as diferenças sociais e os preconceitos ligados às identidades, performatividades e corporalidades estigmatizadas. Branca Moreira Alves e Jacqueline Pitanguy (1985) definem muito bem este alinhamento:

O feminismo se constrói, portanto, a partir das resistências, derrotas e conquistas que compõem a História da Mulher e se coloca como um movimento vivo, cujas lutas e estratégias estão em permanente processo de recriação. Na busca da superação das relações hierárquicas entre homens e mulheres, alinha-se a todos os movimentos que lutam contra a discriminação em suas diferentes formas (ALVES e PITANGUY, 1985, p. 74).

Em síntese, o feminismo tornou-se um projeto crítico do pensamento humanista e dos movimentos sociais com o propósito de defender os direitos e interesses das mulheres e, de maneira mais ampla, em defesa de qualquer identidade, corpo e subjetividade discriminada pela política cisheteropatriarcal. Inicialmente, surgiu no século 19 com a intenção de requerer os direitos básicos das mulheres pelo voto e participação nas universidades. Nesse período, ao homem era permitido se empenhar-se profissionalmente, ser ambicioso e desempenhar papéis em cargos públicos, enquanto para a mulher o destino inevitável era o casamento e a maternidade na vida privada ${ }^{5}$ (MUNFORD, 2008). Com o tempo, ao longo do século 20, o movimento feminista ganhou força e ampliou suas demandas para requerer equidade pela maior integração das mulheres em um mundo dominado pelos homens.

Ao longo da história da sociedade ocidental, a condição das mulheres em relação ao controle de seus corpos, seus deslocamentos e suas sexualidades, definindo regras e tabus para seus comportamentos, foram determinações estabelecidas por homens e amparados pela estrutura patriarcal dominante. Por isso, a violência cotidiana, que vemos ainda hoje, permanece como mecanismo de manutenção desta dominação masculina, em subjugar as mulheres (e qualquer identidade ligada ao feminino) no papel secundário e submisso da sociedade (ÁVILA, 2003).

As primeiras discrepâncias sobre as diferenças marcadas entre homens e mulheres surgidas no século 19, através das funções sociais, impulsionaram as contestações feministas e de outros movimentos identitários na segunda metade século 20. Os movimentos gay e lésbico, por exemplo, foram além dessa problematização dos feminismos de segunda onda ao requererem direitos

\footnotetext{
${ }^{5}$ De acordo com Munford (2008), a expansão dos limites quantitativos, que assinalou o crescimento das cidades do modelo orgânico para o mecânico, também correspondeu ao processo de mecanização do comportamento. Esse aspecto incluiu a incorporação de hábitos relativos às categorias de gênero na sociedade modernista.
}

DOI: http://dx.doi.org/10.22295/grifos.v31i55.6135 | Edição Vol. 31, Núm. 55, 2022. 
igualitários às pessoas homossexuais, desmarginalizando suas sexualidades e demandando o reconhecimento civil e jurídico para as relações entre pessoas do mesmo sexo. De acordo com Peter Fry e Edward MacRae (1985), a consciência de homossexuais ao longo do século 20, motivados pela maior liberdade e autonomia nas grandes cidades ocidentais, define a maior visibilidade dos movimentos gay e lésbico na esfera pública. Segundo os autores, até a Segunda Guerra Mundial, os primeiros debates sobre a condição dos entendidos surgem no contexto cultural europeu. Entretanto, os processos migratórios de áreas periféricas para os centros urbanos também desencadearam processos identitários dissidentes para as comunidades LGBT de países periféricos, como é o caso do Brasil (GOMES, 2019).

Fry e MacRae (1985) ainda relatam que as tentativas de justificar biologicamente o terceiro sexo sofriam embates, considerando esta ideia um crime contra a natureza. Na Inglaterra, a repercussão das repressões contra os homossexuais "iriam retardar em muitos anos o desenvolvimento da emancipação homossexual naquele país, que já era anunciada pelos trabalhos de Havelock Ellis e Edward Carpenter" (FRY e MACRAE, 1985, p. 82). Neste período, os movimentos homossexuais estavam muito vinculados às questões territoriais e urbanas. Para os autores, a manifestação mais emblemática em requerer os direitos aos homossexuais, aconteceu no dia 28 de junho de 1969, na rebelião conhecida como Stonewall, em Nova Iorque, motivada pela revolta de gays, lésbicas, dragqueens, prostitutos e sujeitos marginalizados ao reagirem em conjunto contra as batidas frequentes de policiamento. A ação seguiu de manifestações nos dias posteriores e publicações em jornais feitas por organizações políticas, como a Frente de Libertação Gay. Além dos Estados Unidos, as manifestações seguiram para outros países e, atualmente, a comemoração do Orgulho Gay no dia 28 de junho, através das paradas gays em várias cidades mundo afora, representa uma data comemorativa para o motim da Rebelião de Stonewall (COLLING, 2011; FRY e MACRAE, 1985).

O final da década de 1970 e início de 1980 marcam o fim da chamada Revolução Sexual, pelos movimentos liberacionistas feministas e LGBTI. Apesar das campanhas contra o preconceito, a despatologização da homossexualidade foi seguida de sua repatologização em termos epidemiológicos com o surto da AIDS nos anos de 1980, alcançando, primeiramente, a comunidade gay e, em seguida, toda a sociedade. De acordo com Richard Miskolci (2014), foi a condição epidêmica da AIDS que serviu de subterfúgio para uma nova análise sobre a hegemonia da política heterossexual em termos epistemológicos.

DOI: http://dx.doi.org/10.22295/grifos.v31i55.6135 | Edição Vol. 31, Núm. 55, 2022. 
Apenas a partir dos anos 1990, com o surgimento das primeiras publicações referente à Teoria Queer, surge o questionamento da visão essencialista da heterossexualidade como ordem de classificação hierárquica da sociedade. Enquanto os movimentos feministas e homossexuais dialogavam com a imposição da heterossexualidade como norma irrevogável, a Teoria Queer problematiza a cis-heterossexualidade como essência das relações e dos comportamentos humanos ao desconstruir a noção de normalidade de comportamentos e desejos como parte de uma construção cultural hegemônica. Exemplo disso está no conceito de sucesso construído pela sociedade de consumo e desconstruído por Jack Halberstam (2011) ao problematizar que o sucesso é um advento heteronormativo, assim como a noção de fracasso, e que o valor dado às coisas não possui tanta seriedade quanto os discursos midiáticos apontam. Nesse sentido, o estilo proposto de insucesso sugerido pelo autor a partir da perspectiva queer, permitiria a cada pessoa (em termos de singularidade) fugir das normas do dever e do comportamento disciplinado para aplicar outros propósitos de vida, inclusive, na busca pelos prazeres cotidianos e não rotulados.

Assim, ao elaborar outro domínio sobre a compreensão do gênero e das sexualidades a Teoria Queer define uma posição política e constitui um campo de conhecimento, que acrescenta novas possibilidades para o pensamento contemporâneo sobre a importância da singularidade na constituição do corpo, independente de identidade de gênero, raça e aptidão física. De caráter subversivo, o termo queer define um sujeito estranho dentro de uma realidade homogênea, padronizada, sugerindo rompimentos na interpretação dominante das fronteiras, que definem a realidade do gênero e do sexo como valores socioculturais.

Para Joan Scott (1995), o gênero torna-se uma categoria usada para pensar as relações sociais que envolvem homens e mulheres, relações historicamente determinadas e expressas pelos diferentes discursos sociais e culturais sobre a diferença sexual. De um termo gramatical para compreender uma forma de classificar fenômenos, a designação gênero passou a ser utilizada pelas feministas para enfatizar socialmente as distinções baseadas no sexo e para desenvolver uma categoria de análise.

Considerando a abordagem de gênero no contexto cultural e a de sexo no contexto biológico e anatômico, é importante distinguir a ênfase epistemológica do discurso crítico. Tratar do gênero como perspectiva para um novo olhar requer pensar na maior oportunidade a ser dada para as representações do feminino no âmbito de sexualidades, enquanto orientação e práticas de interação 
social, entre aquelas estigmatizadas e/ou valorizadas no âmbito de quem as pratica e com quem são praticadas (LISBOA, 2014; VELÁZQUEZ, 2003).

Velázquez (2003, p. 13) completa esse entendimento ao considerar que "os estudos de gênero se orientam a analisar criticamente as construções teóricas patriarcais e apontam uma nova forma de questionar a realidade através de novas categorias analíticas para explicar aspectos desta realidade”. Destaco que as concepções identitárias pautadas pelos questionamentos feministas e pelas teorias de gênero, sexualidades e queer, contribuem para a transformação substancial das categorias prévias de identificação estável da modernidade. Esses novos arranjos ambivalentes de identificação e constituição de subjetividades fluídas, organizados em movimentos sociais, costuma gerar insegurança nos meios já consolidados de regulamentação das necessidades humanas e torna inevitável o senso crítico atual contra a justificativa modernista para o cerceamento da sociedade padrão em prol do desenvolvimento ilimitado.

\section{EXPERIÊNCIAS NÃO HEGEMÔNICAS DE URBANIDADE}

O geógrafo Rogério Haesbaert (2014) afirma que as conquistas dos movimentos sociais estiveram relacionadas aos avanços territoriais destes grupos e identidades, obtendo maior mobilidade e visibilidade diante de aberturas e fechamentos nas fronteiras da contenção territorial. Alguns destes aspectos marcam o período de conquistas que caracterizam o movimento feminista de Segunda Onda (PEDRO, 2012), quando os direitos do corpo e da sexualidade tornaram-se assuntos recorrentes nas discussões organizadas entre as mulheres e os movimentos contra sexuais nas publicações e manifestações em espaços públicos. Contudo, a ordem hegemônica pautada na relação de apego aos objetos e aos lugares já consolidados vinculou as demandas dos movimentos feministas e contra sexuais ao direito de apropriação material sem questionar, propriamente, a essência da estrutura e da racionalidade heteronormativa, que atribui o valor aos hábitos de consumo como meio de influenciar a adesão de novas pessoas à herança material da modernidade.

Ao mesmo tempo, é importante considerar que a influência dos movimentos sociais e feministas repercute em atuações coletivas cada vez mais presentes em diferentes contextos culturais e geográficos. Desde comemorações pela aprovação do casamento civil entre pessoas do mesmo sexo, como aconteceu em vários países de Europa desde 2001 e, mais recentemente, nos Estados Unidos em 2015, até as manifestações políticas organizadas por coletivos de mulheres, como 
aconteceu na França e no Brasil; passando, ainda, pelas campanhas e manifestações organizadas por diferentes países da América Latina manifestando o desacordo pelas retrógradas políticas educacionais da campanha "Escola sem partido". Em geral, as experiências recentes do feminismo e das comunidades LGBTI espalhadas nas grandes cidades, mesmo que pontuais ou efêmeras, repercutem sobre os aspectos que regem a vida cotidiana e as redes de comunicação mundial.

Da concepção do sucesso relativo dessas representações surgem manifestações coletivas e públicas que misturam diferentes corpos, identidades de gênero e performatividades humanas para requerer outras demandas sociais e rompendo com os estereótipos de movimentos e representações anteriores. Entre os casos mais reconhecidos está a Marcha das Vadias e a Parada do Orgulho LGBTI, como manifestações coletivas recorrentes, que se espalharam por diversos países e estão presentes na cultural urbana (e midiática) ocidental. Na atualidade, essas manifestações trazem demandas de pessoas transexuais, além da continuidade das problemáticas levantadas pelos movimentos feministas e homossexuais, ao permanecerem como questionamento coletivo de inclusão das diferentes subjetividades e identidades dissidentes no âmbito das vivências urbanas padronizadas pela cis-heterossexualidade.

Mesmo que imbricado com a infraestrutura do planejamento urbano regular e modernista, formando barreiras físicas e jurídicas para novas relações de urbanidade, as experiências subversivas para os modos de viver a cidade continuam presentes e definindo novas dinâmicas, desde a própria constituição dos núcleos familiares, como nos casamentos homoafetivos e poliamorosos, quanto no reconhecimento de comunidades alternativas e autogestionadas. Exemplo disso é o caso da experiência de autogestão comunitária do antigo aeroporto de Tempelhof, que abriga uma grande área livre na malha urbana berlinense (Figura 1). Esse caso emblemático de reapropriação comunitária de uma área urbana consolidada pelos interesses especulativos diz respeito à descentralização das decisões políticas sobre o gerenciamento e uso de áreas de interesse público, voltadas para a manutenção da paisagem urbana e em comum acordo com as decisões plurais de interesses coletivos e individuais da própria comunidade (BOURNAZOU MARCOU, 2018). 


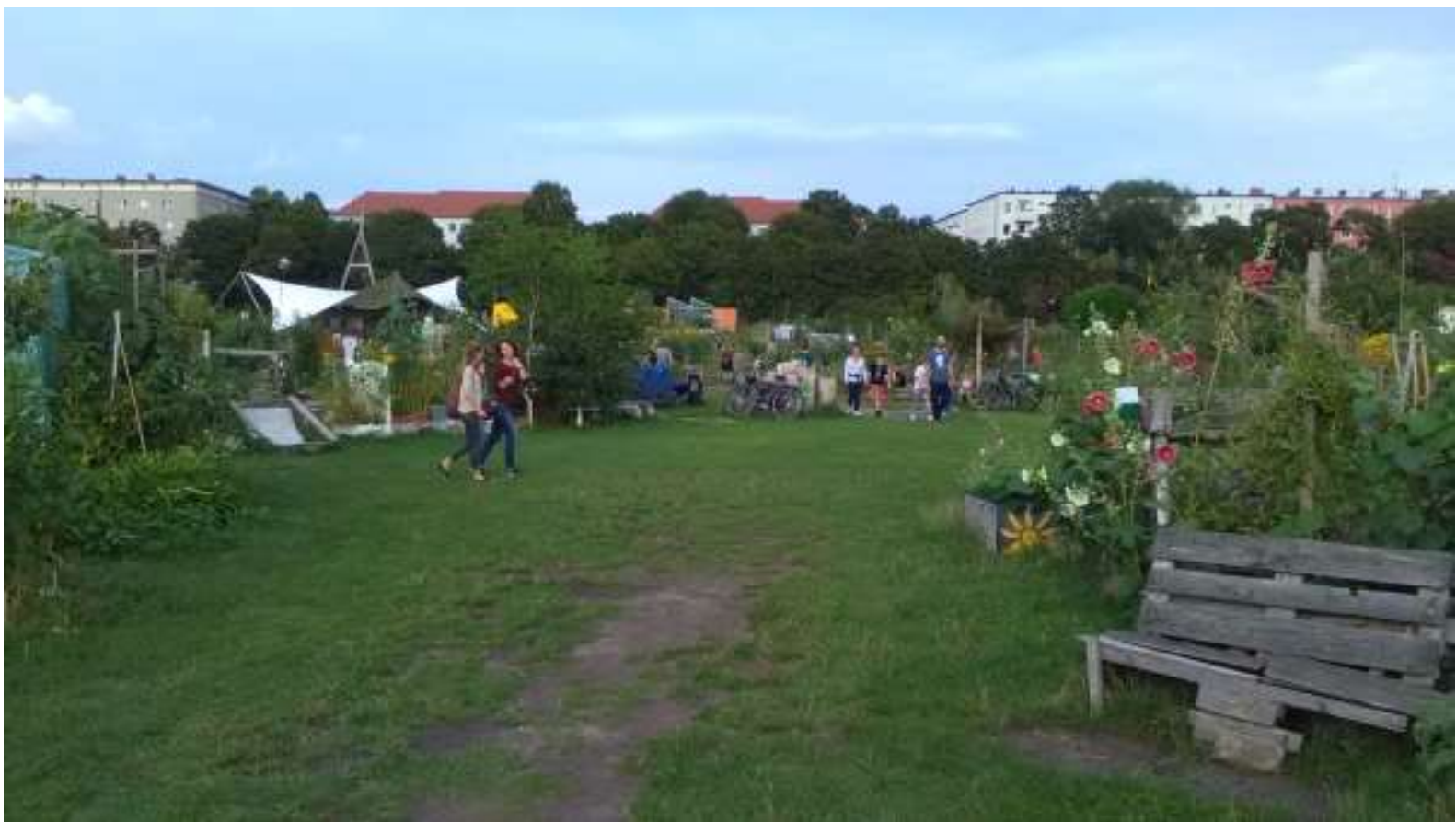

Figura 1. Instalações temporárias no espaço comunitário de Tempelhof, Berlin. Fonte do autor, 2016.

Outro exemplo notório é a apropriação territorial ao estilo squatting ${ }^{6}$ ocorrido há quase cinquenta anos em Christiania, que foi um espaço urbano institucional abandonado de Copenhagen (Figura 2). Na década de 1970 esse local foi invadido por uma comunidade alternativa, que permanece nessa área consolidada até hoje e define um simulacro anti-urbanista vinculado ao contexto de regulamentação e planejamento espacial na capital dinamarquesa. Nessa comunidade a constituição dos núcleos familiares são mais permeáveis às interações comunitárias e às identidades particulares que compõem os meandros da comunidade, inclusive, abrigando um dos principais grupos queer de Copenhagen (JARVIS, 2011).

\footnotetext{
${ }^{6} \mathrm{O}$ squatting refere-se à ação de grupos organizados por movimentos sociais, surgidos nos anos de 1980 e espalhados por cidades europeias, com a intenção de ocupar terrenos vazios e prédios abandonados sem requerer autorização do proprietário e das instituições públicas para sediar suas atividades de grupo ou thes servir como moradia.
}

DOI: http://dx.doi.org/10.22295/grifos.v31i55.6135 | Edição Vol. 31, Núm. 55, 2022.

\section{(अ)}




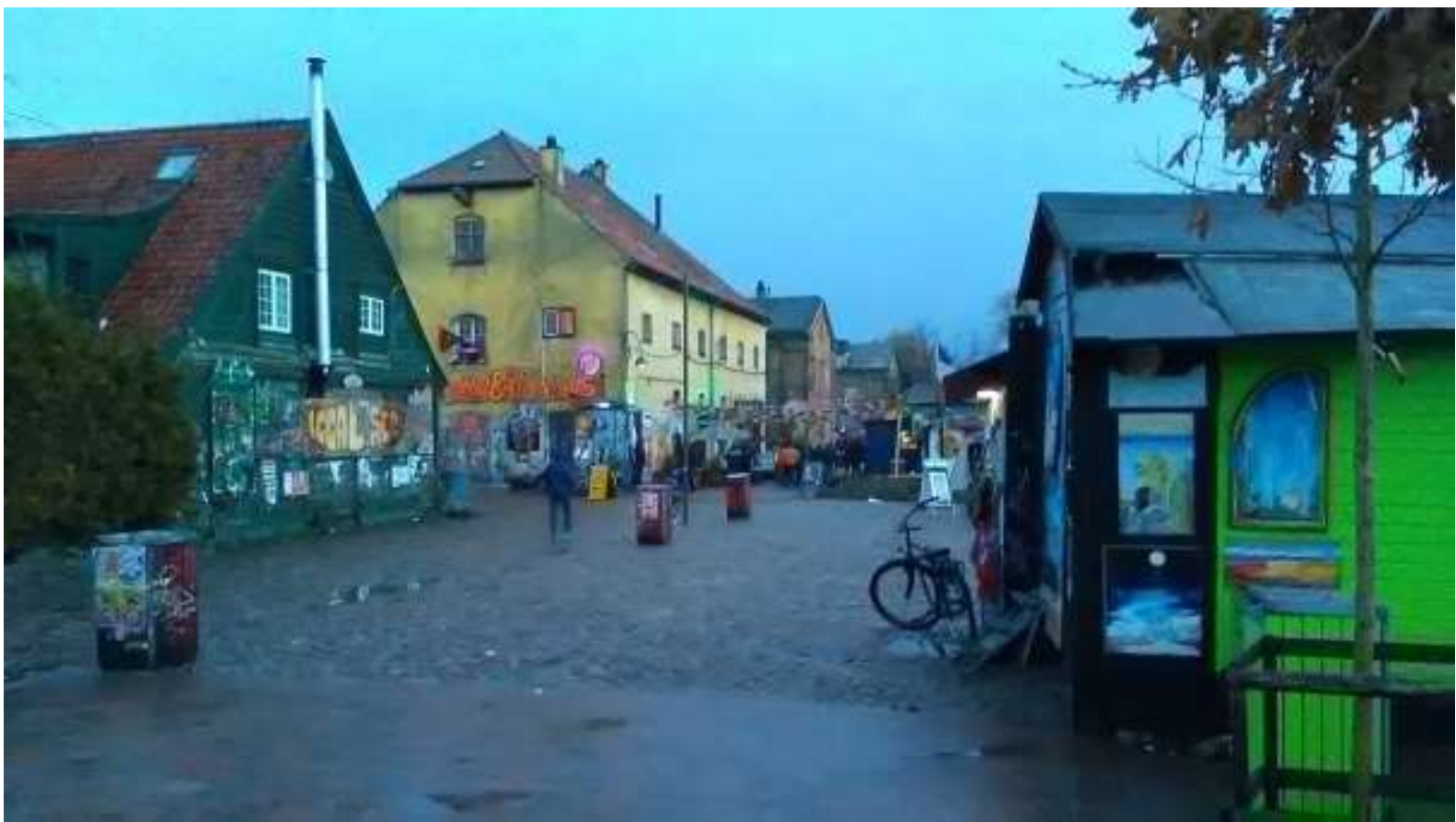

Figura 2. Passagens entre os edifícios de Christiania, Copenhagen. Fonte do autor, 2016.

Ainda, outro exemplo de revitalização dos espaços públicos e comunitários, emblemático no sentido da humanização promovida pelo planejamento urbano, aconteceu há vinte e cinco anos nas cidades de Bogotá e Medellín, na Colômbia. São exemplos que se destacam entre as referências latino-americanas pela melhoria das condições socioculturais dos ambientes urbanos ao mobilizarem políticas públicas efetivas. Foram locais, anteriormente, degradados pela violência e ostracismo dos interesses públicos, mas foram reabilitados na década de 2000 por vários agentes sociais na intenção de atender as demandas dos próprios moradores locais, reduzindo-se o impacto dos processos de exclusão social imediata e futura gentrificação urbana (ANTONUCCI e BUENO, 2018).

Esses exemplos - poucos divulgados como solução para a boas práticas de urbanidade, quem sabe devido ao forte caráter de constituição comunitária e (re)apropriação urbana não-hegemônica são manifestações que envolvem a participação popular na definição dos arranjos espaciais e das representações de grupos alternativos, mobilizados pelo diálogo coletivo e pela atenção dada às necessidades cotidianas. São práticas que envolvem: (a) valores de cooperação coletiva, na formação de habitação e estruturas familiares mais amplas, muitas vezes, distintas do patriarcado; (b) atenção aos hábitos de alimentação e consumo; (c) revisão nos modos de gerar salubridades e produzir resíduos diários; (d) reelaboração da educação e formação cultural de crianças, jovens e adultos a 
partir de suas próprias experiências; (e) perpetuação de atividades e vínculos sociais mais efetivos para a tomada de consciência sobre as demandas por mobilidade e acessibilidade, física e social.

Enfim, dizem respeito às vivências de manutenção e sobrevivência, que, normalmente, estão sob o domínio de mulheres e identidades fluídas, voltadas para o cuidado de si e da cidade, e que apostam suas alternativas de vida em aspectos simples e essenciais na manutenção das boas relações sociais como principal fator de desenvolvimento humano.

\section{APONTAMENTOS FINAIS}

Na medida em que o foco das atuações da sociedade contemporânea mantém o discurso do espaço urbano como cenário principal da produtividade técnica, a concorrência pela territorialização representativa da esfera pública reduz-se à disputa recorrente pelo apego aos lugares e as propriedades para atender aos interesses cis-heteropatriarcais. No entanto, consideramos nesse artigo que os avanços nas teorias sociais e nas Ciências Humanas, como no caso do descentramento total do sujeito cartesiano pela tomada do inconsciente a partir da psicanálise de Freud e, em especial, na ambivalência da performatividade do sujeito fora do padrão interpretado pelas teorias feministas, de gênero e sexualidades, promovem rearranjos dos modos de vida e ampliam as experiências a partir de novos comportamentos, pensamentos e performatividades. Tornam-se, assim, experiências viáveis para a boa convivência social e urbana e como referências para viabilizar políticas públicas e sociais a partir de experiências plurais e legítimas na constituição de urbanidades não hegemônicas (GOMES, 2017).

Ao mesmo tempo em que essas novas categorias subjetivas e identitárias abrem espaço para a representação das diversas maneiras possíveis das pessoas e dos grupos constituírem outras estéticas de existência, essa possível transitoriedade de conceitos e ações também contribui, substancialmente, para o deslocamento de discursos e materialidades na formação de novas redes sociais e processos criativos para outras realizações humanas - apesar da política neoliberal totalizadora pressionar na readaptação constante das novas condições sociais e culturais para atender aos interesses do sistema econômico global, relegando as demandas sociais pela conquista da autonomia e das experiências singulares.

Por fim, a partir das teorias feministas e das teorias de gênero e sexualidades é possível considerar a busca por uma sociedade mais justa e cuidadosa, em respeito às pessoas enquadradas

DOI: http://dx.doi.org/10.22295/grifos.v31i55.6135 | Edição Vol. 31, Núm. 55, 2022. 
no contexto de maior vulnerabilidade de seus corpos e de suas subjetividades. Sem dúvida, este posicionamento político e histórico iniciado pelo(s) feminismo(s), seguido pelos movimentos homossexuais e transexuais, entre tantas outras teorias e experiências sociais, que questionam os significados atribuídos à realidade totalizadora, repercutem positivamente ao constituírem referências válidas para as urbanidades que estão por vir.

\section{REFERÊNCIAS}

ALVES, Branca Moreira; PITANGUY, Jacqueline. O que é feminismo. São Paulo: Editora Abril Cultural: Brasiliense, 1985.

ANTONUCCI, Denise; BUENO, Lucas. A construção do espaço público em Medellín. Quinze anos de experiência em políticas, planos e projetos integrados. Arquitextos, São Paulo, Vitruvius, 2018. Disponível em: http://www.vitruvius.com.br/revistas/read/arquitextos/19.218/7022 Acesso 25 fev. 2021.

ÁVILA, Maria Betânia. Direitos sexuais e reprodutivos: desafios para as políticas de saúde. Cad. Saúde Pública, Rio de Janeiro, 19 (Sup.2), p. 465-469, 2003. Disponível em: http://www.scielo.br/pdf/csp/v19s2/a27v19s2.pdf Acesso 25 fev. 2021.

BAUMAN, Zygmunt. Modernidade e Ambivalência. Rio de Janeiro: Zahar, 1999.

BOURNAZOU MARCOU, Eftychia Danai. Disputas por el espacio público en la planeación neoliberal. La conquista ciudadana de Tempelhof. Bitácora Arquitectura, [S.1.], n. 38, p. 30-41, sep. 2018. Disponível em: http://www.revistas.unam.mx/index.php/bitacora/article/view/67058 Acesso 25 fev. 2021.

COLLING, Leandro (org.). Stonewall 40 + o que no Brasil? Salvador: EDUFBA, 2011.

DARDOT, Pierre; LAVAL, Christian. A nova razão do mundo: ensaio sobre a sociedade neoliberal. Tradução de Mariana Echalar. 1. ed. São Paulo: Boitempo, 2016.

FERNANDES, Ana. Cidades e cultura: rompimento e promessa. In: JEUDY, Henri Pierre. JACQUES, Paola Berenstein (org.). Corpos e cenários urbanos: territórios urbanos e políticas culturais. Tradução Rejane Janowitzer. Salvador: UFBA; PPG-AU/FAUFBA, p. 51-64, 2006.

FOUCAULT, Michel. História da Sexualidade 1: a vontade de saber. Tradução de Maria Thereza da Costa Albuquerque e J. A. Guilhon Albuquerque. 1. ed. São Paulo: Paz e Terra, 2014.

FRY, Peter; MACRAE, Edward. O que é homossexualidade. São Paulo: Abril Cultural/Brasiliense, 1985. 
GOMES, Maurício Pereira. "Se eu passar despercebido o baile não prestou!": Visibilidade e resistência viada no interior de Santa Catarina. 2019. Tese (doutorado). Programa de PósGraduação Interdisciplinar em Ciências Humanas. Florianópolis: UFSC, 2019.

GOMES, Nilma Lino. Políticas públicas para a diversidade. Sapere Aude, v. 8, n. 15, p. 7-22, 22 jul. 2017. Disponível em: https://doi.org/10.5752/P.2177-6342.2017v8n15p7 Acesso em 25 fev. 2021.

HALL, Stuart. A identidade cultural na pós-modernidade. Tradução: Tomaz Tadeu da Silva e Guacira Lopes Louro. 11. ed. Rio de Janeiro: DP\&A, 2006.

HAESBAERT, Rogério. Viver no limite: território e multi/transterritorialidade em tempos de insegurança e contenção. 1. ed. Rio de Janeiro: Bertrand Brasil, 2014.

HALBERSTAM, Judith. The queer art of failure. Durham and London: Duke University Press, 2011.

JARVIS, Helen. Alternative visions of home and family life in Christiania: lessons for the mainstream. In: THÖRN, Hakan; WASSHEDE, Cathrin; NILSON, Tomas (ed.). Space for urban alternatives? Christiania 1971-2011. Copenhagen: Gidlunds Förlag, p. 156-180, 2011.

LIMA, Solange Ferraz de; CARVALHO, Vânia Carneiro de. O corpo na cidade: gênero, cultura material e imagem pública. Estudos Históricos, Rio de Janeiro [on-line], v. 24, n. 48, p. 233-263, 2011. Disponível em: http://dx.doi.org/10.1590/S0103-21862011000200001 Acesso 25 fev. 2021.

LISBOA, Teresa Kleba. Violência de gênero, políticas públicas para o seu enfrentamento e o papel do serviço social. Temporalis, [S.1.], vol. 1, n. 27, p. 33-56, ago. 2014.

LYOTARD, Jean-François. A condição pós-moderna. Tradução Ricardo Corrêa Barbosa. 12. ed. Rio de Janeiro: José Olympio, 2009.

MISKOLCI, Richard. Diversidade ou diferença? Revista Cult, ano 18, n. 205, p. 16-19, 2015.

. Crítica à Hegemonia Heterossexual. Revista Cult, ano 17, n. 193, p. 33-35, 2014.

MUNFORD, Lewis. A cidade na história: suas origens, transformações e perspectivas. Tradução Neil R. da Silva. 5. ed. São Paulo: Martins Fontes, 2008.

PEDRO, Joana Maria. O feminismo de "segunda onda". Corpo, Prazer e Trabalho. In: PINSKY, Carla Bassanezi; PEDRO, Joana Maria (org.). Nova História das Mulheres no Brasil. São Paulo: Contexto, p. 238-259, 2012.

SASSEN, Saskia. The global city: Introducing a concept. Brown Journal of World Affairs, v. XI, Issue 2, p. 27-43, 2005. 
SCOTT, Joan Wallach. Gênero: uma categoria útil de análise histórica. Educação \& Realidade, Porto Alegre, v. 20, n. 2, p. 71-99, 1995.

SPOSITO, Maria Encarnação Beltrão. Capitalismo e Urbanização. 16. ed. São Paulo: Contexto, 2012.

VELÁZQUEZ, Susana. Violencias cotidianas, violencias de género: escuchar, aprender, ayudar. Buenos Aires: Ediciones Paidos Iberica, 2003. 